\title{
Effect of Exercise on ADMA Level in Type 2 Diabetes Mellitus
}

\author{
Bengur Taşkıran'1, Betül Uğur Altun², Selma Arzu Vardar², Ahmet Muzaffer Demir², Çetin Hakan Karadağ², Armağan Altun² \\ ${ }^{1}$ Department of Endocrinology and Metabolic Diseases, Diyarbakır Training and Research Hospital, Diyarbakır, Turkey \\ ${ }^{2}$ Department of Endocrinology and Metabolic Diseases, Faculty of Medicine, Trakya University, Edirne, Turkey
}

\begin{abstract}
Objective: The increase in symmetric (SDMA) and asymmetric dimethyl arginine (ADMA) is associated with endothelial dysfunction. The aim of this study was to evaluate the effect of exercise on ADMA and SDMA levels and related ratios in type 2 DM

Material and Methods: Thirty-six women with type $2 \mathrm{DM}$ and 44 healthy women were recruited to the study. Fourteen and 19 subjects, respectively, attended four-weeks of moderate intensity exercise. Plasma SDMA, ADMA, and L-arginine levels were measured by the HPLC method initially, after the first exercise session, and after one month.

Results: All measurements were within the normal range in both groups and did not change significantly immediately after exercise and after the first month. In the healthy group, L-arginine/ADMA and L-arginine/SDMA ratios after one month were significantly higher than the initial values $(p<0.022$ and $p=0.017$, respectively). After one month of exercise, L-arginine/ADMA and L-arginine/SDMA ratios increased in diabetics and decreased in healthy
\end{abstract} subjects when compared to those after the first exercise session $(p=0.026$ and $p=0.037$, respectively).

Conclusion: We suggest that L-arginine/ADMA and L-arginine/SDMA ratios should be used in spite of absolute values. These molecules have a substantial role in the beneficial effects of exercise in healthy subjects while their role is small in diabetics.

Key Words: ADMA, arginine, exercise, diabetes mellitus type 2

Received: 04.10.2010 Accepted: 05.04.2011

\section{Introduction}

Cardiovascular disease is the leading cause of death in diabetes mellitus (DM), and regular exercise reduces the risk, irrespective of weight loss and glucose control $(1,2)$.

Systemic inflammation decreases and endothelial vasodilation recovers during exercise. One of the systems involved is the nitric oxide (NO) pathway. The most anti-atherogenic substance secreted by the endothelium is NO. It is derived from a semi-essential amino acid, L-arginine (3). NO regulates vascular smooth muscle tone and inhibits many proatherogenic processes such as monocyte and platelet adhesion, low-density lipoprotein oxidation, and synthesis of inflammatory cytokines. In addition, NO increases insulin sensitivity (3).

An L-arginine metabolite, ADMA, is the major endogenous NOS inhibitor (4). L-arginine/ADMA ratio shows NO synthesis $(5,6)$. ADMA is degraded by the enzyme dimethylarginine dimethylaminohydrolase (DDAH). ADMA demolishes endothelium derived flow response substantially (5). Increased ADMA impairs endothelium derived NO mediated vasodilation, enhances monocyte adhesion, and causes platelet hyperaggregation (7).
Plasma ADMA levels increase in many instances related to endothelial dysfuntion such as hypercholesterolemia, atherosclerosis, hypertension, chronic renal insufficiency, chronic heart failure, and smoking $(8,9)$. Furthermore, ADMA increases 2-3 fold in type 2 DM (4, 10-12). L-arginine levels hover in the normal range in these clinical situations where ADMA increases. Thereby the L-arginine/ADMA ratio decreases (3).

Another dimetihylarginine (DMA) compound, SDMA competes with cellular uptake of L-arginine and cannot inhibit NOS. There are reports showing that SDMA as well as ADMA is related to vascular diseases (3). SDMA is more closely related to renal insufficiency compared to ADMA (6). ADMA/SDMA ratio reflects DDAH activity (10). The L-arginine/SDMA ratio is an indicator of renal insufficiency (13). SDMA, which competes with L-arginine for reabsorption, is responsible for the changing ratios in renal insufficiency.

The only research concerning the ADMA level in regularly exercising diabetics was conducted in type $1 \mathrm{DM}$. It was shown that ADMA decreased during regular exercise but the beneficial effect dissipated months after cessation of exercise (14). The ADMA status is obscure in exercising type 2 diabetics. In this study we aimed to evaluate ADMA, SDMA, and L-arginine levels in type $2 \mathrm{DM}$ and their relation to exercise. 


\section{Materials and Methods}

\section{Subjects}

Thirty-six women diagnosed with type 2 DM and 44 healthy women without any known systemic disease (control group) were enrolled in the study (15).

None of the diabetic subjects were on steroid, insulin, nebivolol, or nitrate therapy. The patients with a history of hypertension and those with blood pressure of $\geq 140 \mathrm{mmHg}$ systolic and $\geq 90 \mathrm{mmHg}$ diastolic were recorded as hypertensive. Those who had blood pressure values above $160 / 90 \mathrm{mmHg}$, proliferative diabetic retinopathy, muscle-skeletal disease, chronic renal disease (creatinine clearance calculated in 24 hour urine less than $30 \mathrm{~mL} /$ minute), or liver failure were not included in the study.

The control group had a fasting glucose level below 100 $\mathrm{mg} / \mathrm{dL}$ and 2-hour glucose level less than $140 \mathrm{mg} / \mathrm{dL}$ after 75 $\mathrm{g}$ glucose load. They had a normal blood pressure of less than $140 \mathrm{mmHg}$ systolic and less than $90 \mathrm{mmHg}$ diastolic.

Height, weight, and waist and hip circumference were measured. Body mass index (BMI) was calculated by dividing weight in kilograms by the square of height in meters $\left(\mathrm{kg} / \mathrm{m}^{2}\right)$. Waist/hip ratios were recorded. The subjects with a BMI of 25$29 \mathrm{~kg} / \mathrm{m}^{2}$ were classified as overweight and BMI of $\geq 30 \mathrm{~kg} / \mathrm{m}^{2}$ as obese (16).

TSH and serum insulin were measured by the chemiluminescence immunoassay method (BIO-DPC, Immulite, USA). HDL and total cholesterol and triglyceride levels were measured by spectrophotometry (Beckman Coulter). LDL cholesterol was calculated according to the Friedewald formula [total cholesterol-(triglyceride/5+HDL)]. Creatinine was evaluated by spectrophotometer autoanalyser (MEGA 600, Merck, Germany) using Diasis (Germany) kits. Insulin resistance was calculated using the homeostasis model assessment (HOMAR) formula (17). Hemoglobin $A_{1 c}$ was measured by the immunoassay method.

The study was approved by ethics commitee. Written informed consent was taken from the enrollees.

\section{Exercise protocol}

None of the subjects had participated in a regular exercise programme during the preceeding three months. Fourteen diabetic and 19 healthy subjects attended an exercise programme that consisted of 12 sessions. The daily activities of the subjects who refused to conform to the exercise programme were released. The subjects who did not regularly attend the programme were dropped out of the exercise group.

Fat perecentage was measured before the exercise programme (Tanita Model 300, Tokyo, Japan). In order to determine the intensity of exercise, a submaximal work test was performed and maximal oxygen uptake $\left(\mathrm{VO}_{2 \max }\right)$ was calculated. The exercise programme was tailored individually with an intensity of $40 \% \mathrm{VO}_{2 \text { max }}, 40$ minutes per day, 3 days per week for 4 successive weeks. Exercise intensity was increased in subjects who adhered to the programme. Therefore moderate intensity exercise was considered to be appropriate.

A submaximal work test (Astrand Cycle Ergometer Test) was performed using a computerized ergometer (Monark
894-E, Monark Exercise AB, Sweden). A suitable load was chosen as $300 \mathrm{kpm} / \mathrm{min}$ ( $1 \mathrm{kp}$ and 50 pedal turns) or $600 \mathrm{kpm} /$ $\min (2 \mathrm{kp}$ and 50 pedal turns). The ergometer pedal was ridden for 6 minutes and the heart rate was recorded every minute until the same heart rate was achieved in the successive 2 minutes or the difference between the last two heart rates was a maximum of four. The heart rate was monitored with a chest belt telemetry system (Polar 610i, Monark Exercise AB, Sweden). The values were evaluated in the Modified AstrandRyhming nomogram and $\mathrm{VO}_{2 \max }$ was calculated (18). The test was discontinued when the heart rate of the subjects over 40 years exceeded $150 \mathrm{rpm}$. The load was not allowed to exceed $600 \mathrm{kpm}$.

\section{ADMA, SDMA and L-arginine measurement}

Blood samples taken at 08:30-09:00 am after one night of fasting were collected in ethylene diamine tetra acetic acid (EDTA) containing tubes at the beginning of the study. The alliquots were centrifuged at $5000 \mathrm{rpm}$ for 5 minutes within 30 minutes of collection. The supernatant was stored at $-80^{\circ} \mathrm{C}$ until analysis. The exercise attendees were sampled again within 15 minutes after the first and last session of exercise. Nonexercise subjects were also sampled after one month.

ADMA was determined using the established HPLC method described by Teerlink (19).

\section{Statistical analysis}

Descriptive statistics of the variables and normal distribution was tested by the one-sample Kolmogorov Simirnov test. Clinical variables were analyzed by the Fisher exact test.

Student's t test was used for variables showing normal distribution to evaluate the difference between the two groups. ADMA, SDMA, and L-arginine values and L-arginine/ADMA, $\mathrm{L}$-arginine/SDMA, and ADMA/SDMA ratios at the beginning, after the first and last session of exercise, and after one month were compared by the Bonferroni multiple comparison test within each group (diabetic and control group). Analysis of covariance was used for comparison of the groups.

The values were expressed as mean \pm standard deviation. A p value lower than 0.05 was accepted as being of statistical significance. The statistica 7.0 (Installer Code: 31N6YUCV38) programme was used for statistical analysis.

\section{Results}

Two (9\%) from the diabetic non-exercise group $(n=22)$ and 5 (35\%) from the diabetic exercise group $(n=14)$ had hypertension. One (4\%) subject from the diabetic non-exercise group and $2(14 \%)$ subjects from the diabetic exercise group had non-proliferative retinopathy. Other clinical features and laboratory values are shown in Table 1, 2 .

Among the exercising subjects, 8 diabetic patients and 5 healthy controls were unable to complete the programme. One exercising diabetic had a positive exercise test on the Bruce protocol and underwent coronary angiography. None of the subjects could exercise beyond stage 3 of the Bruce protocol. The most common symptom for discontinuation was tiredness. Angina and hypotension did not occur. 
Table 1. Clinical features and laboratory values of the attendees

\begin{tabular}{|c|c|c|c|c|c|c|c|c|c|}
\hline & \multicolumn{2}{|c|}{$\begin{array}{l}\text { Non-exercising } \\
\text { controls }(n=25)\end{array}$} & \multicolumn{2}{|c|}{$\begin{array}{l}\text { Exercising controls } \\
\qquad(n=19)\end{array}$} & \multicolumn{2}{|c|}{$\begin{array}{l}\text { Non-exercising } \\
\text { diabetics }(n=22)\end{array}$} & \multicolumn{2}{|c|}{$\begin{array}{l}\text { Exercising diabetics } \\
\qquad(n=14)\end{array}$} & $p$ \\
\hline $\mathrm{Age}^{\star}$ & \multicolumn{2}{|c|}{$40.8 \pm 9.3$} & \multicolumn{2}{|c|}{$30.7 \pm 5.7$} & \multicolumn{2}{|c|}{$50.5 \pm 7.9$} & \multicolumn{2}{|c|}{$47.3 \pm 10.7$} & $<0.0001$ \\
\hline Smoking & & 5 & \multicolumn{2}{|c|}{7} & \multicolumn{2}{|c|}{6} & \multicolumn{2}{|l|}{3} & 0.61 \\
\hline Menopause status & & 7 & \multicolumn{2}{|c|}{1} & \multicolumn{2}{|c|}{15} & \multicolumn{2}{|l|}{8} & 0.50 \\
\hline $\mathrm{TSH}(\mathrm{mlU} / \mathrm{L})$ & \multicolumn{2}{|c|}{$1.90 \pm 1.05$} & \multicolumn{2}{|c|}{$2.13 \pm 1.32$} & \multicolumn{2}{|c|}{$2.01 \pm 1.2$} & \multicolumn{2}{|c|}{$2.25 \pm 1.76$} & 0.72 \\
\hline $\begin{array}{l}\text { Total cholesterol } \\
\text { (mg/dL) }\end{array}$ & \multicolumn{2}{|c|}{$192 \pm 42$} & \multicolumn{2}{|c|}{$175 \pm 28$} & \multicolumn{2}{|c|}{$199 \pm 45$} & \multicolumn{2}{|c|}{$186 \pm 38$} & 0.11 \\
\hline $\mathrm{TG}^{\star}(\mathrm{mg} / \mathrm{dL})$ & \multicolumn{2}{|c|}{$115 \pm 41$} & \multicolumn{2}{|c|}{$107 \pm 46$} & \multicolumn{2}{|c|}{$142 \pm 85$} & \multicolumn{2}{|c|}{$127 \pm 45$} & 0.03 \\
\hline LDL (mg/dL) & \multicolumn{2}{|c|}{$119 \pm 40$} & \multicolumn{2}{|c|}{$105 \pm 28$} & \multicolumn{2}{|c|}{$128 \pm 38$} & \multicolumn{2}{|c|}{$110 \pm 30$} & 0.31 \\
\hline $\mathrm{HDL}^{*}(\mathrm{mg} / \mathrm{dL})$ & \multicolumn{2}{|c|}{$51 \pm 12$} & \multicolumn{2}{|c|}{$49 \pm 13$} & \multicolumn{2}{|c|}{$42 \pm 8$} & \multicolumn{2}{|c|}{$48 \pm 10$} & 0.02 \\
\hline HbA1c (\%) & & & & & $7.58 \pm$ & \pm 1.53 & $7.67 \pm 1$ & 1.18 & 0.42 \\
\hline $\operatorname{Ccr}(\mathrm{mL} / \mathrm{min})$ & & & & & $85.59 \pm$ & \pm 30.96 & $92.82 \pm 1$ & 16.63 & 0.54 \\
\hline Ccr group ${ }^{\star \star}$ & & & & & $1: n=14,2: r$ & $n=5,3: n=6$ & $1: n=5,2: n=$ & $6,3: n=3$ & 0.43 \\
\hline MAU & & & & & $9(4$ & $0 \%)$ & $2(14$ & & 0.09 \\
\hline $\mathrm{VO}_{2 \max }{ }^{*}(\mathrm{~mL} / \mathrm{kg} / \mathrm{mir}$ & & & 34.4 & \pm 8.9 & & & $17.4 \pm$ & 3.4 & $<0.0001$ \\
\hline Fat free mass $(\mathrm{kg})$ & & & 48.5 & \pm 5.1 & & & $47.1 \pm$ & 5.9 & 0.46 \\
\hline Fat mass ${ }^{\star}(\%)$ & & & 25.6 & \pm 7.8 & & & $41.0 \pm$ & 6.2 & $<0.0001$ \\
\hline & Initial & $1^{\text {st }}$ month & Initial & $1^{\text {st }}$ month & Initial & $1^{\text {st }}$ month & Initial & $1^{\text {st }}$ month & \\
\hline Waist* $(\mathrm{cm})$ & $95.8 \pm 10.9$ & $96.05 \pm 11.7$ & $88.5 \pm 11.5$ & $87.7 \pm 10.7$ & $99.5 \pm 8.5$ & $100.3 \pm 10.0$ & $109.0 \pm 10.8$ & $112.6 \pm 12.0$ & $<0.0001,0.001$ \\
\hline WHR & $0.90 \pm 0.05$ & $0.91 \pm 0.05$ & $0.90 \pm 0.07$ & $0.90 \pm 0.06$ & $0.92 \pm 0.07$ & $0.93 \pm 0.07$ & $0.95 \pm 0.07$ & $0.95 \pm 0.06$ & $0.09,0.09$ \\
\hline $\mathrm{BMI}^{\star}\left(\mathrm{kg} / \mathrm{m}^{2}\right)$ & $29.9 \pm 5.1$ & $29.8 \pm 11.7$ & $25.6 \pm 4.7$ & $25.01 \pm 4.4$ & $33.0 \pm 4.9$ & $32.1 \pm 4.3$ & $35.4 \pm 6.3$ & $38.3 \pm 8.3$ & $<0.0001,<0.0001$ \\
\hline HOMAR & & & & & $4.5 \pm 4.2$ & $4.7 \pm 1.8$ & $3.9 \pm 1.1$ & $8.6 \pm 9.9$ & $0.002,0.007$ \\
\hline
\end{tabular}

There was no correlation between ADMA and age in contrast to the previous data (20). There was a positive correlation between SDMA and age (beta=0.226, $p=0.044$ ). These relations did not affect L-arginine/ADMA, L-arginine/SDMA, and ADMA/SDMA ratios.

Creatinine clearance was measured only in the DM group. There was a negative correlation between creatinine clearance and SDMA (beta $=-0.477, p=0.003$ ) and between creatinine clearance and ADMA (beta $=-0.482, p=0.003$ ). This correlation reflected on the ADMA/SDMA ratio as a positive correlation (beta $=0.348)(p=0.037)$. Even though $L$-arginine was not correlated with creatinine clearance, there was a positive correlation between creatinine clearance and the L-arginine/ SDMA ratio (beta $=-0.343, p=0.04$ ). There was no correlation between creatinine clearance and the L-arginine/ADMA ratio.

The initial mean ADMA, L-arginine, and SDMA levels and ADMA/SDMA L-arginine/ADMA and L-arginine/SDMA ratios did not differ significantly in diabetic and healthy subgroups (Table 2). After the first exercise session, these values did not change significantly compared from the initial values. At the end of one month ADMA, L-arginine, and SDMA levels and ADMA/SDMA ratio did not change significantly either.

The only change was observed in the exercising control group at the end of one month. The L-arginine/ADMA ratio increased significantly from the initial value in comparison to the other 3 groups [non-exercising control, $(p=0.004)$; non-exercising diabetics $(p=0.022)$; exercising diabetics $(p=0.001)$ ]. On the contrary, The L-arginine/ADMA ratio decreased in the exercising control group while it increased in the exercising diabetic group compared to the value obtained at the end of the first exercise session $(p=0.026)$.

After the first month, the L-arginine/SDMA ratio was significantly higher than the initial value in the exercising control group only in comparison to the non-exercising control groups $(p=0.017)$. When compared to the values obtained at the end of the first exercise session, L-arginine/SDMA ratios decreased in the exercising control group while it increased in the exercising diabetic group $(p=0.037)$.

\section{Discussion}

It is known that ADMA plays a role in decreased NO production in DM, but the levels vary a great deal according to the method and sample used. Serum ADMA levels are $60-70 \%$ higher than plasma levels. Results with ELISA are higher than the gold standard HPLC method (3). Therefore there is contradictory data about ADMA levels. Most of the studies showed higher ADMA levels in type 2 DM $(11,21,22)$, while others yielded normal levels $(4,20,24,25)$. Inhibiton of DDAH by hyperglycemia and advanced glycosylated products was blamed 
Table 2. Measurements at three time-points. ADMA, SDMA, and L-arginine values are expressed in micromolar units ( $\mu$ M)

\begin{tabular}{|c|c|c|c|c|}
\hline & $\begin{array}{l}\text { Non-exercising } \\
\text { controls }\end{array}$ & Exercising controls & $\begin{array}{c}\text { Non-exercising } \\
\text { diabetics }\end{array}$ & Exercising diabetics \\
\hline \multicolumn{5}{|l|}{ Initial } \\
\hline ADMA & $0.51 \pm 0.18$ & $0.52 \pm 0.14$ & $0.56 \pm 0.20$ & $0.56 \pm 0.12$ \\
\hline SDMA & $0.40 \pm 0.17$ & $0.40 \pm 0.09$ & $0.42 \pm 0.15$ & $0.41 \pm 0.20$ \\
\hline Arginine & $65.1 \pm 23.6$ & $68.8 \pm 29.7$ & $70.0 \pm 30.2$ & $82.3 \pm 53.0$ \\
\hline Arginine/ADMA & $137.9 \pm 56.7$ & $128.9 \pm 36.0$ & $128.9 \pm 43.5$ & $139.1 \pm 63.5$ \\
\hline Arginine/SDMA & $199.8 \pm 155.3$ & $168.2 \pm 54.3$ & $182.7 \pm 84.2$ & $158.8 \pm 32.4$ \\
\hline ADMA/SDMA & $1.38 \pm 0.49$ & $1.31 \pm 0.25$ & $1.40 \pm 0.36$ & $1.30 \pm 0.50$ \\
\hline \multicolumn{5}{|c|}{ First exercise session } \\
\hline ADMA & - & $0.47 \pm 0.23$ & - & $0.58 \pm 0.18$ \\
\hline SDMA & - & $0.37 \pm 0.09$ & - & $0.37 \pm 0.18$ \\
\hline Arginine & - & $83.3 \pm 40.6$ & - & $87.2 \pm 34.5$ \\
\hline Arginine/ADMA & - & $171.7 \pm 59.7$ & - & $152.8 \pm 49.9$ \\
\hline Arginine/SDMA & - & $221.2 \pm 91.4$ & - & $238.2 \pm 129.4$ \\
\hline ADMA/SDMA & - & $1.28 \pm 0.23$ & - & $1.48 \pm 0.37$ \\
\hline \multicolumn{5}{|l|}{ First month } \\
\hline ADMA & $0.55 \pm 0.12$ & $0.46 \pm 0.11$ & $0.53 \pm 0.18$ & $0.57 \pm 0.10$ \\
\hline SDMA & $0.43 \pm 0.14$ & $0.36 \pm 0.11$ & $0.41 \pm 0.12$ & $0.50 \pm 0.20$ \\
\hline Arginine & $72.9 \pm 26.5$ & $92.9 \pm 49.3$ & $65.6 \pm 31.3$ & $69.0 \pm 24.4$ \\
\hline Arginine/ADMA* & $136.3 \pm 51.4$ & $187.9 \pm 58.1$ & $122.1 \pm 49.6$ & $119.0 \pm 35.8$ \\
\hline Arginine/SDMA ${ }^{\star \star}$ & $181.0 \pm 70.9$ & $248.4 \pm 91.6$ & $166.1 \pm 71.0$ & $156.9 \pm 86.9$ \\
\hline ADMA/SDMA & $1.33 \pm 0.24$ & $1.31 \pm 0.25$ & $1.34 \pm 0.36$ & $1.26 \pm 0.40$ \\
\hline \multicolumn{5}{|c|}{$\begin{array}{l}\text { *First month vs initial values: } \\
\text { Exercising controls vs. Non-exercising controls, } p=0.004 \\
\text { Exercising controls vs. Non-exercising diabetics, } p=0.022 \\
\text { Exercising controls vs. exercising diabetics, } p=0.001 \\
{ }^{* *} \text { First month vs initial values: } \\
\text { Exercising controls vs. Non-exercising controls } p=0.017\end{array}$} \\
\hline
\end{tabular}

$(23,24)$. In our study ADMA and SDMA levels did not differ between healthy control and diabetic subjects. We did not observe a 2-3 fold increase as described in previous reports $(3,10)$

ADMA decreases as hyperglycemia is controlled (26) and is in negative relation with $\mathrm{HbA} 1 \mathrm{c}$ levels (20). Our $\mathrm{HbA} 1 \mathrm{c}$ results were lower than these studies. We did not find any correlation between ADMA and SDMA levels and $\mathrm{HbA}_{1 \mathrm{c}} \mathrm{A}_{\text {certain }}$ level of glycemia may affect the ADMA level.

ADMA increases in renal failure due to decreased excretion and decreased DDAH activity $(7,24)$. ADMA is higher in type 2 diabetics with hyperfiltration than in non-diabetic subjects (20). In our study, all diabetic patients had a creatinine clearance over $30 \mathrm{~mL} / \mathrm{min}$. Creatinine clearance was negatively correlated with ADMA and SDMA levels. This negative correlation reflected on the ADMA/SDMA ratio as a positive correlation (beta $=0.348, p=0.037$ ). In other words, since the SDMA was decreased to a greater extent than the increase in ADMA, a positive correlation was detected between their ratio and creatinine clearance. Therefore, it may be concluded that SDMA increases more than ADMA and is a better indicator of renal clearance. This result is compatible with the rela- tion detected between renal clearance and ADMA and SDMA levels in the literature $(3,12,20,24)$.

Since ADMA levels might overlap in healthy people and patients, it is advised that the L-arginine/ADMA ratio should be used instead $(3,5)$. In our study mean L-arginine levels and L-arginine/ADMA ratios of healthy control and diabetic subjects were compatible with the literature.

There are three reports in the literature about how regular exercise affects ADMA. Mittermayer et al. (14) studied type 1 DM patients and found that ADMA decreased after regular exercise and therefore L-arginine/ADMA ratio increased, similar to our study. The effect continued months after cessation of exercise. There was no healthy control group in that study.

In the study carried out by Gomes et al. (27), 18 patients with metabolic syndrome attended a 3 month exercise programme. Age and gender matched healthy control subjects did not participate in exercise programme. The groups did not differ in terms of the ADMA level. After 3 months, ADMA increased in the non-exercise group, while it decreased significantly in the exercise group. Exercise may induce NO production via increased blood flow and vascular stress. The increased NO level was proposed to be responsible for the 
decrease of ADMA after exercise. OGTT was not done to exclude DM and plasma glucose levels of the exercise group were in the range of prediabetes. The mean age of the enrollees was higher than our subjects. ADMA levels as high as $1.5 \mu \mathrm{M}$ even in the healthy group were above the expected normal levels. The L-arginine/ADMA ratio was not stated. This may be due to the ELISA method used.

In a study by Niebauer et al. (28), after an 8 week exercise programme, ADMA and L-arginine measured by HPLC increased, while SDMA and L-arginine/ADMA ratio decreased in patients with chronic heart failure and increased in the healthy group. These changes were not statistically significant. It was suggested that ADMA compensatorily incresed due to enhanced NOS enzyme activity in heart failure. The mean age of the enrollees was higher than ours. There is no data in that report about glucose metabolism status (fasting plasma glucose or OGTT).

In our study ADMA decreased in the exercising healthy control group. The decrease was more prominent after the first exercise session. The decrease after one month of regular exercise was smaller. In contrast, ADMA increased after the first exercise session in the exercising DM group. ADMA decreased after one month of regular exercise although it remained higher than the initial levels. SDMA decreased to a greater extent in the healthy control group than in the DM group after one month of regular exercise. L-arginine increased in the exercising healthy control group, and increased in the exercising DM group. Although changes in ADMA, SDMA, and $L$-arginine levels did not reach statistical significance, the ratios between them (L-arginine/ADMA and L-arginine/ SDMA) differed significantly. The most prominent increase observed in exercising healthy control subjects suggested that healthy control subjects benefited most from the exercise. In $D M$, there may be other protective pathways besides the NOS system components (ADMA, SDMA, and L-arginine) that are operational in the effect of exercise on hypertension, weight, body fat composition, and glycemic control.

Our exercising subjects did not experience significant weight loss at the end of the one month exercise programme. Similarly, a meta-analysis of 12 studies done by Boulé et al. (2) revealed no significant weight loss in type $2 \mathrm{DM}$ patients admitted to an aerobic exercise programme of more than 8 weeks of duration. Boulé proposed that exercise was not carried out frequently enough and for sufficient duration to provide weight loss. The author also suggested that body composition was not recorded in these studies and the fat mass lost with exercise might be compensated for by fat free mass. In another meta-analysis of aerobic exercise studies (29), fat mass was measured by magnetic resonance imaging, and abdominal visceral fat mass decreased by $48 \%$ and abdominal subcutaneous fat mass by $18 \%$. In our study, the number of diabetic patients completing the exercise programme was not large enough to draw a conclusion about the change in body composition.

Our study is the first that evaluated the effect of regular exercise on ADMA, SDMA, and L-arginine levels in type 2 DM. We suggest that L-arginine/ADMA and L-arginine/SDMA ratios should be used to evaluate th NOS system instead of their absolute levels. Although the components of the NOS system plays a master role in regressing atherosclerosis in exercising healthy people, its importance decreases in DM. Exercise programmes of longer duration and a larger number of diabetic patients are needed to reach a final decision.

\section{Conflict of Interest}

No conflict of interest was declared by the authors.

\section{References}

1. American Diabetes Association. Nutrition recommendations and interventions for diabetes: a position statement of the American Diabetes Association. Diabetes Care 2007;30 Suppl 1:S48-65. [CrossRef]

2. Boulé NG, Haddad E, Kenny GP, Wells GA, Sigal RJ. Effects of exercise on glycemic control and body mass in type 2 diabetes mellitus: a meta-analysis of controlled clinical trials. JAMA 2001;286:1218-27. [CrossRef]

3. Bode-Böger SM, Scalera F, Ignarro LJ. The L-arginine paradox: Importance of the L-arginine/asymmetrical dimethylarginine ratio. Pharmacol Ther 2007;114:295-306. [CrossRef]

4. Kawata T, Daimon M, Hasegawa R, Teramoto K, Toyoda T, Sekine $T$, et al. Effect of angiotensin-converting enzyme inhibitor on serum asymmetric dimethylarginine and coronary circulation in patients with type 2 diabetes mellitus. Int J Cardiol 2009;132:286-8. [CrossRef]

5. Vallance P, Leone A, Calver A, Collier J, Moncada S. Accumulation of an endogenous inhibitor of nitric oxide synthesis in chronic renal failure. Lancet 1992;339:572-5. [CrossRef]

6. Bode-Böger SM, Scalera F, Kielstein JT, Martens-Lobenhoffer J, Breithardt G, Fobker M, et al. Symmetrical dimethylarginine: a new combined parameter for renal function and extent of coronary artery disease. J Am Soc Nephrol 2006;17:1128-34. [CrossRef]

7. Blardi P, de Lalla A, Pieragalli D, de Franco V, Meini S, Ceccatelli $L$, et al. Effect of iloprost on plasma asymmetric dimethylarginine and plasma and platelet serotonin in patients with peripheral arterial occlusive disease. Prostaglandins Other Lipid Mediat 2006;80:175-82. [CrossRef]

8. Böger $\mathrm{RH}$. Asymmetric dimethylarginine (ADMA) and cardiovascular disease: insights from prospective clinical trials. Vasc Med 2005;10 Suppl 1:S19-25. [CrossRef]

9. Oguz A, Uzunlulu M, Yorulmaz E, Yalçin Y, Hekim N, Fici F. Effect of nebivolol and metoprolol treatments on serum asymmetric dimethylarginine levels in hypertensive patients with type 2 diabetes mellitus. Anadolu Kardiyol Derg 2007;7:383-7.

10. Abbasi F, Asagmi T, Cooke JP, Lamendola C, McLaughlin T, Reaven GM, et al. Plasma concentrations of asymmetric dimethylarginine are increased in patients with type 2 diabetes mellitus. Am J Cardiol 2001;88:1201-3. [CrossRef]

11. Sugai $M$, Ohta $A$, Ogata $Y$, Nakanishi M, Ueno $S$, Kawata $T$, et al. Asymmetric dimethylarginine (ADMA) in the aqeous humor of diabetic patients. Endocr J 2007;54:303-9. [CrossRef]

12. Malecki MT, Undas A, Cyganek K, Mirkiewicz-Sieradzka B, Wolkow $P$, Osmenda $G$, et al. Plasma asymmetric dimethylarginine (ADMA) is associated with retinopathy in type 2 diabetes mellitus. Diabetes Care 2007;30:2899-901. [CrossRef]

13. Fleck C, Schweitzer F, Karge E, Busch M, Stein G. Serum concentrations of asymmetric (ADMA) and symmetric (SDMA) dimethylarginine in patients with chronic kidney diseases. Clin Chim Acta 2003;336:1-12. [CrossRef]

14. Mittermayer F, Pleiner J, Krzyzanowska K, Wiesinger GF, Francesconi M, Wolzt M. Regular physical exercise normalizes elevated asymmetrical dimethylarginine concentrations in patients 
with type 1 diabetes mellitus. Wien Klin Wochenschr 2005;117: 816-20. [CrossRef]

15. American Diabetes Association. Diagnosis and classification of diabetes mellitus. Diabetes Care 2008;31 Suppl 1:S55-60. [CrossRef]

16. World Health Organization. Physical status: the use and interpretation of anthropometry: report of a WHO expert committee. World Health Organ Tech Rep Ser 1995;854:1-452.

17. Matthews DR, Hosker JR, Rudenski AS, Naylor BA, Treacher DF, Turner RC. Homeostasis model assessment: insulin resistance and $\beta$-cell function from fasting plasma glucose and insulin concentrations in man. Diabetologia 1985;28:412-9. [CrossRef]

18. Teräslinna $P$, Ismail AH, MacLeod DF. Nomogram by Astrand and Ryhming as a predictor of maximum oxygen intake. J Appl Physiol 1966;21:513-5.

19. Teerlink T, Nijveldt RJ, de Jong S, van Leeuwen PA. Determination of arginine, asymmetric dimethylarginine, and symmetric dimethyllarginine in human plasma and other biological samples by high-performance liquid chromatography. Anal Biochem 2002;303:131-7. [CrossRef]

20. Päivä H, Lehtimäki T, Laakso J, Ruokonen I, Rantalaiho V, Wirta O, et al. Plasma concentrations of asymmetric-dimethyl-arginine in type 2 diabetes associate with glycemic control and glomerular filtration rate but not with risk factors of vasculopathy. Metabolism 2003;52:303-7. [CrossRef]

21. Yamagishi S, Ueda S, Nakamura K, Matsui T, Okuda S. Role of asymmetric dimethylarginine (ADMA) in diabetic vascular complications. Curr Pharm Des 2008;14:2613-8. [CrossRef]

22. Surdacki A, Stochmal E, Szurkowska M, Bode-Böger SM, Martens-Lobenhoffer J, Stochmal A, et al. Nontraditional atherosclerotic risk factors and extent of coronary atherosclerosis in patients with combined impaired fasting glucose and impaired glucose tolerance. Metabolism 2007;56:77-86. [CrossRef]
23. Yamagishi S, Ueda S, Okuda S. A possible involvement of crosstalk between advanced glycation end products (AGEs) and asymmetric dimethylarginine (ADMA), an endogenous nitric oxide synthase inhibitor in accelerated atherosclerosis in diabetes. Med Hypotheses 2007;69:922-4. [CrossRef]

24. Krzyzanowska K, Mittermayer F, Shnawa N, Hofer M, Schnabler J, Etmüller $Y$, et al. Asymmetrical dimethylarginine is related to renal function, chronic inflammation and macroangiopathy in patients with Type 2 diabetes and albuminuria. Diabet Med 2007;24:81-6. [CrossRef]

25. Makino H, Doi K, Hiuge A, Nagumo A, Okada S, Miyamoto Y, et al. Impaired flow-mediated vasodilatation and insulin resistance in type 2 diabetic patients with albuminuria. Diabetes Res Clin Pract 2008;79:177-82. [CrossRef]

26. Yasuda S, Miyazaki S, Kanda M, Goto Y, Suzuki M, Harano $Y$, et al. Intensive treatment of risk factors in patients with type-2 diabetes mellitus is associated with improvement of endothelial function coupled with a reduction in the levels of plasma asymmetric dimethylarginine and endogenous inhibitor of nitric oxide synthase. Eur Heart J 2006;27:1159-65. [CrossRef]

27. Gomes VA, Casella-Filho A, Chagas ACP, Tanus-Santos JE. Enhanced concentrations of relevant markers of nitric oxide formation after exercise training in patients with metabolic syndrome. Nitric Oxide 2008;19:345-50. [CrossRef]

28. Niebauer J, Clark AL, Webb-Peploe KM, Böger R, Coats AJS. Home-based exercise training modulates pro-oxidant substrates in patients with chronic heart failure. Eur J Heart Fail 2005;7:183-8. [CrossRef]

29. Boulé NG, Kenny GP, Haddad E, Wells GA, Sigal RJ. Metaanalysis of the effect of structured exercise training on cardiorespiratory fitness in type 2 diabetes mellitus. Diabetologia 2003;46:1071-81. [CrossRef] 